Document downloaded from:

http://hdl.handle.net/10251/108072

This paper must be cited as:

Chavarro, D.; Tang, P.; Rafols, I. (2017). Why researchers publish in non-mainstream journals: Training, knowledge bridging, and gap filling. Research Policy. 46(9):1666-1680. doi:10.1016/j.respol.2017.08.002

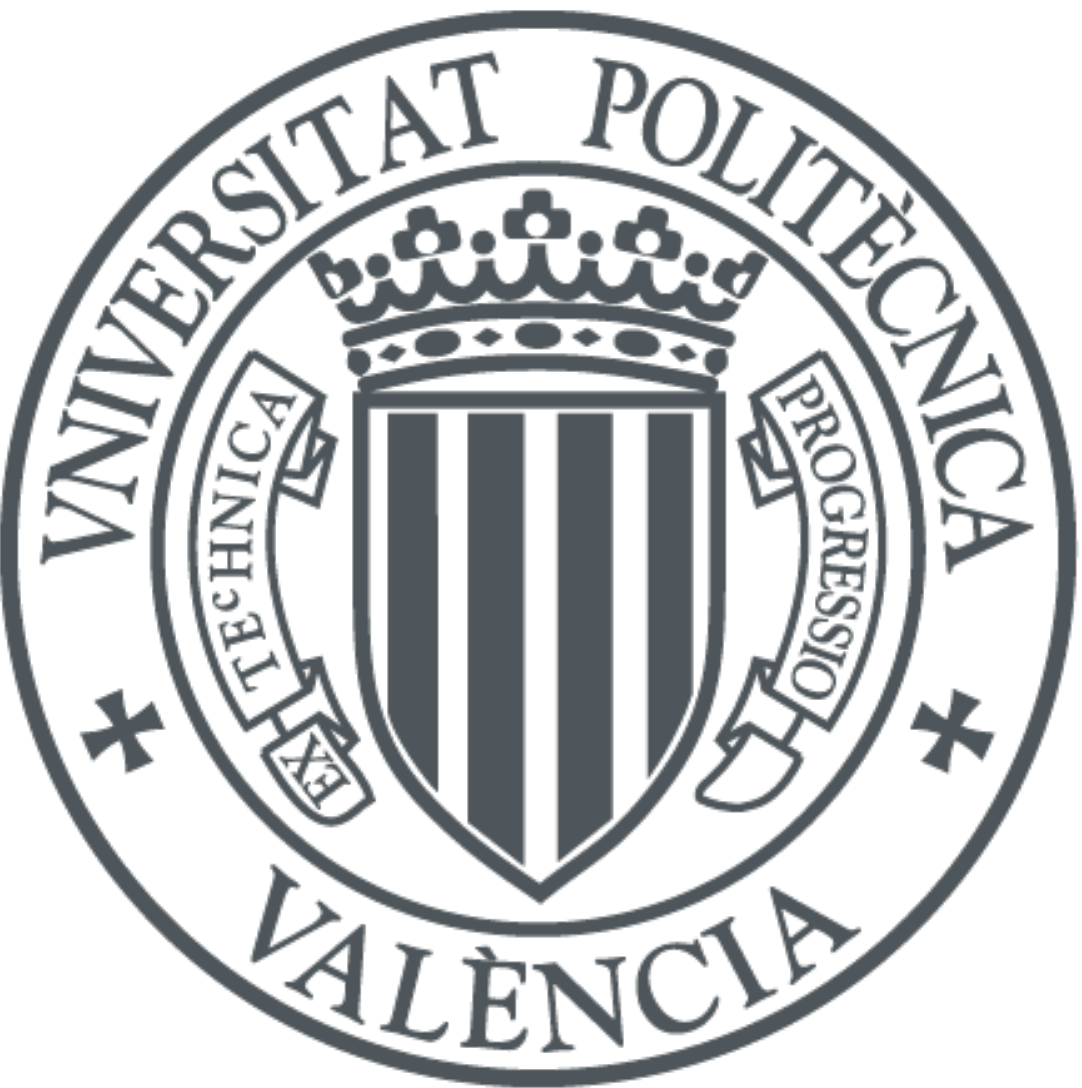

The final publication is available at

https://doi.org/10.1016/j.respol.2017.08.002

Copyright Elsevier

Additional Information 
Research paper

\title{
Why researchers publish in non-mainstream journals: Training, knowledge bridging, and gap filling
}

\author{
Diego Chavarro $^{\mathrm{a}, *}$, Puay Tang ${ }^{\mathrm{a}}$, Ismael Ràfols ${ }^{\mathrm{a}, \mathrm{b}}$ \\ a SPRU (Science Policy Research Unit), University of Sussex, Brighton BN1 9SL, UK \\ ${ }^{\mathrm{b}}$ Ingenio (CSIC-UPV), Universitat Politècnica de València, València 46022, Spain
}

\section{A R T I C L E I N F O}

\section{Keywords:}

Research evaluation

Science communication system

Universalism

Mainstream journals

Non-mainstream journals

Publication patterns

\begin{abstract}
A B S T R A C T
In many countries research evaluations confer high importance to mainstream journals, which are considered to publish excellent research. Accordingly, research evaluation policies discourage publications in other nonmainstream journals under the assumption that they publish low quality research. This approach has prompted a policy debate in low and middle-income countries, which face financial and linguistic barriers to access mainstream journals. A common criticism of the current evaluation practices is that they can hinder the development of certain topics that are not published in mainstream journals although some of them might be of high local relevance. In this article, we examine this issue by exploring the functions of non-mainstream journals in scientific communication. We interviewed researchers from agricultural sciences, business and management, and chemistry in Colombia on their reasons to publish in non-mainstream journals. We found that non-mainstream journals serve the following functions: 1 ) offer a space for initiation into publishing (training); 2) provide a link between articles in mainstream journals and articles read by communities with limited access to them (knowledge-bridging); 3) publish topics that are not well covered by mainstream journals (knowledge gap-filling). Therefore, publication in non-mainstream journals cannot be attributed only to 'low scientific quality' research. They also fulfil specific communication functions. These results suggest that research evaluation policy in low and middle-income countries should consider assigning greater value to non-mainstream journals given their role in bridging and disseminating potentially useful and novel knowledge.
\end{abstract}

\section{Introduction}

In many countries, there is an increasing pressure to prove the value of publicly funded research in order to respond to policy demands for accountability (Whitley and Gläser, 2007). Quantitative forms of research monitoring or assessment are often used as a means to convey to policy-makers, stakeholders, and the wider public the relative performance of researchers, laboratories, universities, and national science systems (Hicks et al., 2015; Wilsdon et al., 2015; Rafols et al., 2016a,b). Many of these assessments use indicators based on data of publications in mainstream journals, that is, journals perceived to publish excellent research, which are typically indexed by the citation databases Web of Science (WoS) and Scopus (Vessuri et al., 2014). In contrast, articles published in other journals receive less recognition in research assessments under the assumption that they publish poor quality articles. Here, we refer to them as non-mainstream journals.

The higher rank attributed to research published in mainstream journals in evaluation in comparison to non-mainstream journals has motivated a long-standing debate. In Latin America, which serves as the geographical focus of this article, it is often assumed that non-mainstream journals do not have satisfactory editorial standards and scientific impact, which render them unsuitable for publication of quality research (Arvanitis and Gaillac, 1992; Vessuri, 1995; Meneghini and Packer, 2007; Aguado-López et al., 2014). An influential blogger, for instance, has called them 'publication favelas' (Beall, 2015). However, some scholars have argued that non-mainstream journals offer a valuable communications channel for research that is neglected in mainstream journals (see debates between Velho and Krige, 1984 and Moravcsik, 1987; Spinak, 1996 and Garfield 1997; Beall, 2015 and Scielo, 2015). The relevance of this debate to research policy is that it reveals a potential underestimation of the knowledge contained in nonmainstream journals by conventional research assessments and agendas (Bianco et al., 2016). We address such a concern by examining the role of non-mainstream journals in scientific communication in the light of

\footnotetext{
* Corresponding author.

E-mail addresses: dchavarro@gmail.com (D. Chavarro), p.tang@sussex.ac.uk (P. Tang), i.rafols@ingenio.upv.es (I. Ràfols).

${ }^{1}$ We recognise that some journals indexed by WoS and Scopus might be less mainstream than others, but given the stronger effects on evaluation for those not-indexed, here we take a dichotomous definition based on indexation.
} 
an increasing policy support to publishing in mainstream journals (Vessuri et al., 2014).

This article investigates the motivations of researchers to publish in non-mainstream journals and the functions of these journals in scientific communication. We obtained main insights from in-depth interviews with 30 Colombian researchers from agricultural sciences, business and management (B\&M), and chemistry. Colombia is an interesting case because it exhibits both a trend of an increasing number of articles in mainstream journals and an important production of nationally edited journals. Our work contributes to existing research on scientific communication systems by identifying three functions fulfilled by non-mainstream journals: training, knowledge bridging, and knowledge gap-filling. These functions provide a richer understanding of the role of non-mainstream journals in a global environment that demands policy support of more relevant and responsible research (Bortagaray and Ordóñez-Matamoros, 2012).

\section{Reasons to publish and journal functions}

Journals are the communication channels for peer-reviewed publications produced by specific research communities. Within each community, the certification of knowledge is done by recognised members who judge the soundness of contributions according to criteria that conform to the norm of universalism (Merton 1973b, pp. 270-272). Universalism is the appraisal of contributions based on objective scientific standards, for instance, compliance with methods accepted in a discipline and derivation of robust conclusions from the findings (Polanyi, 2000, pp. 5-6). This implies that particular characteristics of the person who produces the knowledge, such as their nationality, language, or professional standing, should not influence the appraisal of research (Merton 1973b, pp. 270-272). In this sense, publication of an article in a journal is seen as an objective (thus universal) indicator of its scientific quality within a research field as judged by peers (Zuckerman and Merton, 1971, pp. 66-75). By publishing in journals, researchers contribute to advance knowledge in their field and gain scientific recognition as a reward (Merton, 1973a). Therefore, from the Mertonian sociology of science perspective, the functions of a journal are to serve the communication needs of a scientific community, to certify the quality of contributions and to give scientific recognition to the research community that uses it for publishing.

Research communities are embedded in specific social contexts, for example in geographical, linguistic, and disciplinary contexts, which influence what a research community considers as subjects of interest in their research field and as good scholarship standards (Gläser and Laudel, 2016, Hess, 2016, p. 162). For instance, medical researchers located in South America may have a particular interest in studying tropical diseases, whereas the 'international' community (with a majority of North American and European researchers) may be more inclined to have an interest on cancer research (Evans et al., 2014). In addition, some research communities may value contributions to knowledge because of the rigour of their methodology or the novelty of their results (such as in high-energy physics), whereas other communities may value more their potential contribution to perceived societal problems. As journals serve the communication needs of research communities in specific contexts, they are likely to reflect their contextual interests and standards. In particular, editors and peer-reviewers act as gatekeepers who set the direction of their research field and decide who makes part of their community through their authority on publication (Crane, 1967; Myers, 1985).

However, researchers usually belong to more than one community. For instance, lecturers in B \& M located in Colombia are part of the Latin American community, but often they form part of the European or North American communities too. Having distinct (though generally overlapping) communities, the question of understanding the functions of journals becomes also a question of understanding the specific community and thus the type of audience that a researcher is addressing in each publication. Each journal is an entrance, guarded by editors and reviewers, to recognition by a specific community with very specific epistemic and social contexts. For example, Piñeiro and Hicks (2014) showed for Spanish sociology that the most cited articles in WoS and in the Spanish citation database IN-RECS differed radically in their subjects. The authors interpreted this difference as resulting from the different audiences addressed: 'foreign' in the case of journals covered by WoS, and 'domestic' in the case of journals covered by IN-RECS.

Within a given scientific community, researchers tend to share common views about journal quality. Some journals are perceived as more rigorous or important, and are awarded more prestige than other journals. The existence of a ranking of journals might be plausible within a given research community when publishing is only about communication within the community and for scientific recognition in a universalistic Mertonian ethos. However, the possibility of rankings of research quality based on objective and purely scientific criteria is not possible when comparing different scientific communities. ${ }^{2}$ This is because scientific disciplines abide by different quality criteria and therefore are incommensurable (Kuhn, 1963). Thus, peer review does not work when peers are not in the same field or from the same research community (Weinberg, 1963, p. 162).

Based on the consideration that journals are communication channels for specific research communities, and that these communities are affected by their social contexts, it is plausible to assume that researchers choose the journals to publish according to the fit between the content and style of the text and the audiences of the journal (Myers, 1985, Bazerman, 1988, p. 4). Hicks (2004) clearly illustrated that in the case of the social sciences and the humanities, the choice is not only between journals (e.g. international vs. national), but also between books and the press, with each communication channel addressing a different audience. Therefore, the choice of a journal by a researcher is not only guided by considerations of knowledge advancement and peer recognition. Our research aims to uncover other motivations for publishing decisions by researchers, which may include activities valued by the specific community, such as addressing some particular societal needs.

In addition to these motivations, a new driver for publication has arisen from the advent of research evaluation systems for managerial purposes. These systems have created notions of performance as measured by expertise external to science, which have decoupled career advancement from traditional peer recognition (Paradeise and Thoenig, 2013). In particular, they have transformed publishing into an indicator of scientific performance that is increasingly important for career advancement (Whitley and Gläser, 2007). Many research evaluation frameworks use journal classifications as proxies for scientific quality, thus creating notions of mainstream and non-mainstream science from them. Therefore, there is a potential misalignment between perceptions of quality by the local research communities, and implementations of quality assessments by evaluation systems. The following section addresses this topic.

\section{Research evaluation systems and journal quality}

Non-mainstream journals in Latin America have had very low public policy support under the assumption that they publish low quality research (Vessuri, 1995). On many occasions, measures have been implemented to promote publication in 'top' journals thus discouraging publication in non-mainstream journals (Vessuri, 1995; Cetto et al., 2010) which are considered by some as 'adding noise' to scientific communication (Garfield, 1995). However, these journals have continued to develop in Latin America, which is one of the regions with a

\footnotetext{
${ }^{2}$ For example, the Leiden Manifesto for research metrics (Hicks et al., 2015) warns that different fields, local contexts or missions of science cannot be compared using the same bibliometric indicators. To do so, one needs to make strong assumptions on the relative value of contributions or citations across fields.
} 
greater production of papers in non-mainstream journals in the world (Chavarro, 2017, chapter 5). A question that arises then is whether nonmainstream journals serve communication functions relevant to their local or national research communities. In this section we confront this question with a broader discussion on the dominant use of research evaluation to explore two different perspectives on the role of nonmainstream journals.

The first perspective, which we call 'universalistic', is reflected in the exclusive use of mainstream journals in formal research evaluation, which implicitly acknowledges them as authorities that can judge the production and 'quality' of scientific contributions. Following this view, in evaluation systems, mainstream journals are seen as defining mainstream science (Guédon, 2001, 2007), in practice, they are perceived as setting quality standards for all research. As discussed, the use of mainstream journals for this kind of research evaluation implies a notion of research quality according to which 'quality' can be objectively assessed regardless of the context (disciplines, languages, places) in which it is produced. Therefore, this notion of quality relates to the understanding of universalism as a "homogenising" principle that allows objective appraisals of science.

This type of universalistic research evaluations has put pressure on researchers to publish in mainstream journals. Mainstream journals are frequently identified as those covered by WoS (Davis and Eisemon, 1989; Nagpaul, 1995; Guédon, 2001; Meneghini et al., 2006) and Scopus (Lemarchand, 2010; Aguado-López et al., 2014). In other words, indexing in these databases has become a source for global reputation and recognition for journals, and thus indirectly for researchers publishing in those journals.

In Central and Southern Europe, for instance, publishing in journals covered by WoS has become a requirement to show the quality of papers in formal evaluation (Lillis and Curry, 2010; Rafols et al., 2016a,b). This is also the case in regions, such as Latin America, in which publishing in journals covered by WoS and Scopus has become an indication of scientific excellence (Vessuri et al., 2014). For example, in Brazil, the score of a publication (Qualis) submitted to the quality assessment of graduate schools (Capes ${ }^{3}$ ) is often related to the database in which the journal is covered. This is because the Qualis scoring is based on a journal classification in which indexing in WoS or Scopus is a positive criterion in most disciplines (Frigeri 2012, p. 15, p. 63, Mugnaini, 2015). The Colombian system, Publindex, is similar to the Qualis model of Capes. Charum (2004) published a categorisation of databases that has been used as the basis for ranking journals, papers and researchers for the purposes of deciding on public funding in that country. Journals covered by WoS and Scopus in the top citation quartiles receive the highest scores.

Bibliometrics is not the only type of indicator taken into account by all research evaluation systems, but the above examples illustrate the use of databases to define journal quality, and the use of journals to define research quality. In summary, dominant research evaluation systems promote publications in mainstream journals (especially in those indexed by WoS), because it is perceived that these journals certify the quality of scientific contributions and endow high recognition to scientists.

The second perspective, which we refer to as 'contextual', assumes that journals are linked to the research contexts and interests of specific research communities. This perspective criticises the use of journal classifications for research evaluation because it does not recognise the importance of context in research production (Bianco et al., 2016). Researchers have expressed concern that the majority of mainstream journals are English language journals from the natural sciences produced in the US, the UK, and the Netherlands (Gibbs, 1995; van Leeuwen et al., 2001; Klein and Chiang, 2004; Larivière and Macaluso, 2011; Rafols et al., 2016a,b; Larivière et al., 2015). This implies that

\footnotetext{
3 http://capes.gov.br/avaliacao.
}

research evaluations based on mainstream journals may underestimate the knowledge produced in other regions, languages, and disciplines. The consequence of this underestimation is that certain research topics may receive less attention. Moreover, many authors have expressed concerns that important issues may not even be studied because of the lack of reputational and financial incentives derived from conventional research evaluations and agendas (Hess 2007, 2017, p. 132; Vessuri et al., 2014; Bianco et al., 2016).

Controversies emerge from the confrontation between the universalistic and the contextual perspectives on journals. Concerning research assessment in Colombia the construction of national classification of journals for research evaluation (Publindex) has generated virulent public debates. In 2016, for example, a group of approximately 100 well-known researchers signed an open letter to the Colombian research council (Colciencias) requesting a strict classification based exclusively on the Journal Citation Reports (JCR) for all disciplines (Delgado et al., 2016). Another group of around 50 equally prestigious researchers signed a response to this letter criticising the use of the JCR to derive universalistic quality measures (Gómez-Morales et al., 2016).

Notice that, in spite of their differences the two perspectives on journals do not exclude each other. Both universalistic and contextual understanding of quality may concur and affect the publication decisions of researchers (Fry et al., 2009, p. 91). This is because researchers may be part of different research communities and play multiple social roles. As explained by Hicks (2004), for example, some researchers may aim to make a scientific contribution and look for scientific recognition among their US and EU peers (universalistic Mertonian drivers), yet as professionals of their national research community, they are required to be accountable to employers, and as citizens they are concerned about their society (contextual drivers).

To recap, from the dominant (universalistic) perspective of formal research evaluation systems, non-mainstream journals are seen as venues for poor quality research. From a more contextualised view, nonmainstream journals are seen as communication venues that are important for certain research communities and their audiences. The contrasting but potentially concurrent views offer a starting point to further investigate the functions of non-mainstream journals in scientific communication (Estrada-Mejía and Forero-Pineda, 2010) at a historical time in which journal-based research evaluation is becoming increasingly more formalised and controlling (Whitley and Gläser, 2007, 2012; Burrows, 2012), as well as more widely questioned (DORA, 2013; Hicks, 2015, Stirling 2015, p. 12).

\section{Methodology}

We examined the publishing practice of researchers from agricultural sciences, B \& M, and chemistry in Colombia. This country shows a growing number of publications in mainstream (Lemarchand, 2012) and non-mainstream journals (OCyT, 2015). The OECD classifies Colombia as an upper-middle income country and an S \& T developing country (Ordóñez-Matamoros et al., 2010). It produces about 500 journals, an amount comparable to Brazil (1500), Argentina (500) and Mexico (360) (Chavarro, 2017, p. 107). As in other countries in Latin America, most of its academic publishing houses are higher education institutions.

In order to collect information from mainstream and non-mainstream journals and corroborate publishing patterns we used bibliographic databases. The most well known are WoS (until recently part of the information corporation Thomson-Reuters, now run by Clarivate Analytics) and Scopus (part of Elsevier's publishing group). These databases are widely used as authoritative data sources (Lemarchand, 2010). Additionally, we used Scielo and RedALyC as the leading examples of databases for non-mainstream journals in Latin America. These systems are regional databases that index journals mainly from Latin America, Spain, and Portugal that are not covered or partially covered by WoS and Scopus (Chavarro, 2017, p. 153). 
We applied the following procedures to inquire why researchers publish in non-mainstream journals: (1) identified and analysed the publication patterns of selected researchers; (2) conducted an interview program; (3) codified interview data; and (4) contrasted interview data with publication patterns. Researchers were identified and selected using CvLAC. This is a Curriculum Vitae database of Colombian researchers managed by Colciencias, the main public funding agency for science in Colombia. The criteria to select researchers were: those (1) participating in a research group endorsed by a Colombian organisation certified by Colciencias; (2) with a $\mathrm{PhD}$; and (3) with an individual production of at least five papers in the last 10 years. Sixty researchers were contacted, 30 formal interviews were conducted with 10 for each discipline.

The publication patterns of each researcher from CvLAC were analysed in terms of the number of papers produced in journals indexed by RedALyC, Scielo, Scopus, or WoS. This information was contrasted and complemented with the researchers' web profiles and other publicly available CVs. An updated CV was obtained from the researchers themselves, which was then compared to Colciencia's CvLAC. The comparison showed that CvLAC only provided a complete list of publications for the sample until 2012. ${ }^{4} \mathrm{~A}$ few publications were lacking from some researchers, but they were updated using Scielo, RedALyC, WoS, Scopus, and the CVs provided by the researchers. In other cases, CvLAC was more up to date than the researchers' own CVs. Finally, the list of publications was organised into tables and aggregated for each researcher. This allowed an understanding of their publication patterns from matching the journals with databases covering them (WoS, Scopus, RedALyC, and Scielo), producing a list of mainstream and nonmainstream journals.

We then conducted 30 interviews from May to September 2013 in Colombia. The reasons for the choice of researchers from agricultural sciences, B \& M, and chemistry are 1) the differences in the journal coverage of these disciplines by WoS and Scopus; and 2) the degree to which the research findings of these disciplines are affected by the research context. Regarding coverage, chemistry is generally well covered by journals in WoS and Scopus, which implies a lesser need for nonmainstream journals in chemistry, as compared to agricultural sciences, and B \& M. Regarding the research context, chemistry is usually assumed independent of socio-cultural and geographical environments (Cole, 1983). In contrast, knowledge in agriculture is considered to be highly localised. Therefore it may influence and be influenced by the local context of production (Velho, 1985). Because of fierce competition for reputation among B \& M schools, lecturers in these fields face pressure to publish in specific journals to perform well in journal rankings (Rafols et al., 2012). Table 1 below illustrates the diversity of backgrounds of researchers in the sample.

The interview program was designed to inquire why researchers publish and why they do so in non-mainstream journals with an emphasis on journals covered by Scielo and RedALyC. It also explored their views on Scielo, RedALyC, and associated non-mainstream journals. Researchers were encouraged to talk freely. Later analysis allowed identifying if there was any mention of mainstream journals, journal indexing databases or related subjects such as impact factors or journal rankings, how they search for relevant literature, how they decide to publish in different journals, and how they ranked their papers according to their definition of contribution to knowledge. The interviews followed a semi-structured, open-ended questionnaire. This questionnaire is available in the supplementary material file 1 (questions 1-6 and 10-13 especially).

Twenty-eight of the interviews were recorded. We used the method known as thematic analysis (Braun and Clarke, 2006), which consists of taking notes while interviewing and journalising them after the interview. This was then followed by listening to the audio files, identifying

\footnotetext{
${ }^{4}$ The interviews took place in 2014.
}

Table 1

Distribution of researchers interviewed.

\begin{tabular}{lll}
\hline Sector $^{\mathrm{a}}$ & Private university & 19 \\
& Public university & 11 \\
Experience $^{\mathrm{b}}$ & Senior & 17 \\
& Junior & 13 \\
Gender $^{\mathrm{c}}$ & Women & 9 \\
& Men & 21 \\
Nationality & Colombian & 26 \\
& Other (one German, one Cuban, two Venezuelan) & 4 \\
\hline
\end{tabular}

\footnotetext{
${ }^{\text {a }}$ Based on the year of the interviews (2014). Researchers may have worked in different sectors previously.

${ }^{\mathrm{b}}$ Senior researchers were considered as those with publishing experience before 1995 and within the age bracket of 50 and 70 .

c The lack of gender balance was due to the availability of respondents. It also reflects the general distribution of researchers in Colombia by gender (OCyT, 2015, p. 47).
}

categories, and validating the categories found through a second review of them (Braun and Clarke, 2006). The categories helped with the identification of publishing patterns, the discovery of themes, and a comparison of responses. We complemented these responses with secondary data sources as noted above.

\section{Findings}

\subsection{Why researchers publish}

How do non-mainstream journals relate to the motivations to publish of Colombian researchers? We first asked the researchers about their work and motivations. Most researchers said that they publish because of scientific recognition and contribution to knowledge (24 researchers). These reasons are related to the Mertonian idea that a publication is a novel finding certified by peers and communicated to the global scientific community. We also found a group of 20 researchers whose main motivation was related to university requirements, monetary incentives, career development, and increased access to funding. In addition to the two perspectives above, a minority of researchers mentioned other motivations. Specifically, six of them said explicitly that they publish in order to have an impact on society. The impacts they want to achieve are related to improving farming practices, developing industries, and using publications in teaching. The respondents were from $\mathrm{B} \& \mathrm{M}$ and agricultural sciences. Table 2 shows the distribution:

An issue of interest is that a contribution to knowledge can be defined in different ways: novelty, usefulness, applicability, among others. We asked researchers to clarify their understanding. Researchers from agricultural sciences and B \& M were more concerned about the contribution of their publications to society than chemists. The latter are focused almost exclusively on novelty, as shown in Table 2.

In summary, contribution to knowledge and career advancement are the main reasons to publish in the sample, with scientific recognition and contribution to society only being relevant to about $20-23 \%$ of the sample. Career advancement is associated with publishing in 'top' journals and therefore not related to non-mainstream. Contribution to knowledge could also relate to communication with peers in mainstream journals. However, as shown in the next section, an analysis of the narratives behind the motivations reveals that non-mainstream journals are indeed used both by many researchers for career advancement (training, see below) and for communicating contributions to knowledge (bridging and gap-filling, also see below).

\subsection{The functions of non-mainstream journals}

In a second set of questions, we inquired the researchers about whether and why they publish in non-mainstream journals. The findings below are descriptions of publishing patterns found in the interviews. We corroborated and expanded the information gathered from 
Table 2

Motivations for publication.

\begin{tabular}{lllll}
\hline Discipline & $\begin{array}{l}\text { Scientific } \\
\text { recognition }\end{array}$ & $\begin{array}{l}\text { Contribution } \\
\text { to knowledge }\end{array}$ & $\begin{array}{l}\text { Career } \\
\text { advancement }\end{array}$ & $\begin{array}{l}\text { Contribution } \\
\text { to society }\end{array}$ \\
\hline $\begin{array}{c}\text { Agricultural } \\
\text { sciences }\end{array}$ & 3 & 9 & 7 & 3 \\
B \& M & 0 & 6 & 7 & 3 \\
Chemistry & 4 & 8 & 6 & 0 \\
Total & & 24 & 20 & 6 \\
\hline
\end{tabular}

Note: One researcher may have multiple motivations.

the interviews, as suggested by Yin, 2009, pp. 114-119) that is using (1) the CVs of the researchers in the sample; (2) data from Scielo, RedALyC, WoS, and Scopus; and (3) the analysis of specific papers mentioned by the researchers.

Two main perceptions of non-mainstream journals emerged from the interviews. One group of researchers considered them as training mechanisms in order to publish in mainstream journals, thereby conferring a low importance to them. The other group considered that nonmainstream journals have the same importance as mainstream journals in terms of the knowledge covered. Here we provide the distillation of the insights in terms of three main motivations or reasons. We refer to them as training, knowledge bridging, and knowledge gap-filling. Training is the use of non-mainstream journals for initiation into publishing. Knowledge bridging is the incorporation of knowledge published in mainstream journals in non-mainstream journals that reach readers with limited access to mainstream journals. Knowledge gap-filling is the publication of topics that are not well covered by mainstream journals.

\subsubsection{Training}

The responses of a group of researchers suggest that publishing in non-mainstream journals is a useful step for building capacity for publishing in mainstream journals. This is based on the idea, expressed by a senior chemist, that 'WoS is a synonym for quality'. For this respondent, although non-mainstream journals are training mechanisms for new researchers, 'the problem is that many researchers get stuck in that stage and never evolve towards the good journals'. Similarly, a researcher from agricultural sciences said: 'For me, when I publish in a journal indexed by Web of Science, it is the best that I can achieve'. Even an editor of a journal on agricultural sciences indexed by Scielo said that 'the role of this journal is to train researchers in order to publish in international journals [meaning WoS-indexed journals]'.

In total, 14 researchers (47\%) considered non-mainstream journals as a step towards publishing in mainstream journals. They used metaphors that implied a chronologically linear sequence for building publishing capacity. These researchers suggested that non-mainstream journals give a 'kick start' to their careers. For instance, a junior researcher from B \& $\mathrm{M}$ in a private university compared the progression from publishing non-mainstream journals to mainstream journals to advancement of one's education level: 'as when you go from primary school, to high school, to university, you have to go through that process to publish in the big leagues'. Another researcher from chemistry referred to non-mainstream journals as a 'staircase'. Yet another researcher from agronomy called them a 'pathway' to WoS. In all cases, there is an implication of a start and an end in terms of qualitative change. Non-mainstream journals represent the start and mainstream journals the end.

Eight researchers from the three disciplines also expressed the idea of training. They said that they use non-mainstream journals to introduce PhD students to academic publications. For instance, a senior researcher in chemistry said that lately he had started publishing in non-mainstream journals to initiate his doctoral students into academic publishing. The advantage is that they can write and communicate with editors and peer reviewers in Spanish. Publishing in these journals also acquaints doctoral students with the peer review system as well as introduce them to the process of literature search.

To summarise, researchers argued that they publish in non-mainstream journals because:

Function 1. Non-mainstream journals are useful as training for researchers to publish in mainstream journals. The papers they publish in non-mainstream journals incorporate feedback from peer reviewers, which contributes to improving other papers that will be submitted to mainstream journals.

Function 2. Non-mainstream journals are also useful to introduce $\mathrm{PhD}$ students to academic publishing in their own language and how to search for relevant literature.

However, other researchers considered that publishing in nonmainstream journals should not be regarded only as a step towards publishing in mainstream journals but as relevant communication media for scientific research. For instance, a researcher from chemistry thought that being a mature scientist meant one had to decide on the type of readership one wanted and then to choose journals to reach that readership. He, however, admitted that he chose the journals in which he publishes from the set covered by WoS or Scopus. He expressed this dilemma in the following way:

I feel that researchers, based on God knows what, have prostituted ourselves. By prostitution, I mean that researchers are guided by the score in rankings, by career improvement, and by the economic benefits of that. In that sense, if you see my CV, since 2006 I have made every effort to publish in WoS or Scopus-indexed journals. It may sound bad, but I only target ISI [WoS] or Scopus. ... Going against the mainstream can be meaningless.

Similarly, a researcher who is also an editor of a B \& M journal indexed by Scielo thought that the pressure to publish in mainstreamindexed journals discourages the formation of distinctive scientific communities in Latin America. For him, non-mainstream journals would find it difficult to become something else other than 'transit stations' to WoS: 'If we are all going towards the same point, I don't think journals here will be able to make progress in those indexing systems. I have doubts that there is real dialogue between the journals from here and the ones from there'. The two comments show that some researchers question the strong focus of research evaluation on mainstream journals, and suggest that there are cases in which non-mainstream journals are more suitable than mainstream for publications that address the interests of their research community and their intended readership. Therefore, researchers may follow alternative publication patterns to sequential publication towards mainstream journals. This implies that the training publication pattern towards mainstream journals does not exhaust the functions of these journals on scientific communication.

To corroborate the interview data on publication patterns, we looked at the CVs of all researchers in the sample. Firstly, we examined the chronology of their publications, and identified the databases covering the journals in which they had published. We then classified every journal article in their CVs as not indexed when we could not find them in Scielo, RedALyC, WoS, or Scopus; indexed in Scielo or RedALyC; and indexed in WoS or Scopus. Finally, we compared their first year of publication to their latest one to identify any changes. Table 3 shows the publication patterns of researchers. When a researcher had both types of publications in the same year, we identified them with the label 'non- and mainstream'. We classified the patterns into three main publication 'pathways' to understand how the patterns support the training hypothesis.

Table 3 shows three main pathways. The first was followed by 14 researchers who started publishing in non-mainstream journals and made a transition to mainstream journals in their latest publications. The majority were from agricultural sciences, followed by B \& M and chemistry. This publication pattern supports the notion that nonmainstream journals are used as training arenas to publish in mainstream journals. 
Table 3

Publication patterns of researchers interviewed, based on initial and latest publications. Source: Own elaboration based on researchers' CVs and Scielo, RedALyC, Latindex, Scopus, and WoS databases. Dates of publications are between 1968 and 2014.

\begin{tabular}{|c|c|c|c|c|c|c|}
\hline Pathways & Start & End & Agr & B \& $M$ & Chem & Total \\
\hline \multirow[t]{4}{*}{$\begin{array}{l}\text { 1.Towards } \\
\text { mainstream }\end{array}$} & $\begin{array}{l}\text { Non- } \\
\text { mainstream }\end{array}$ & Mainstream & 1 & 0 & 2 & 3 \\
\hline & $\begin{array}{l}\text { Non- } \\
\text { mainstream }\end{array}$ & $\begin{array}{l}\text { Non and } \\
\text { Mainstream }\end{array}$ & 5 & 4 & 0 & 9 \\
\hline & $\begin{array}{l}\text { Non and } \\
\text { Mainstream }\end{array}$ & Mainstream & 1 & 1 & 0 & 2 \\
\hline & \multicolumn{2}{|c|}{ Subtotal } & 7 & 5 & 2 & 14 \\
\hline \multirow[t]{4}{*}{ 2. Constant } & Mainstream & Mainstream & 0 & 0 & 3 & 3 \\
\hline & $\begin{array}{l}\text { Non- } \\
\text { mainstream }\end{array}$ & $\begin{array}{l}\text { Non- } \\
\text { mainstream }\end{array}$ & 0 & 3 & 0 & 3 \\
\hline & $\begin{array}{l}\text { Non and } \\
\text { Mainstream }\end{array}$ & $\begin{array}{l}\text { Non and } \\
\text { Mainstream }\end{array}$ & 2 & 0 & 5 & 7 \\
\hline & \multicolumn{2}{|c|}{ Subtotal } & 2 & 3 & 8 & 13 \\
\hline \multirow{3}{*}{$\begin{array}{l}\text { 3. Towards } \\
\text { non- } \\
\text { mainstream }\end{array}$} & Mainstream & $\begin{array}{l}\text { Non and } \\
\text { Mainstream }\end{array}$ & 0 & 1 & 0 & 1 \\
\hline & $\begin{array}{l}\text { Non and } \\
\text { Mainstream }\end{array}$ & $\begin{array}{l}\text { Non- } \\
\text { mainstream }\end{array}$ & 1 & 1 & 0 & 2 \\
\hline & \multicolumn{2}{|c|}{ Subtotal } & 1 & 2 & 0 & 3 \\
\hline Total & & & 10 & 10 & 10 & 30 \\
\hline
\end{tabular}

Note: Mainstream = Indexed in WoS or Scopus. Non-mainstream $=$ Not Indexed in WoS or Scopus. Agr = agricultural sciences, B \& $\mathrm{M}=$ Business and Management, Chem = chemistry; numbers refer to number of researchers; 'start' is their initial publication; 'end' is their latest publication.

However, the other two pathways in Table 3 (which are followed by 16 researchers) do not support the sequential pattern from non-mainstream to mainstream journals. The second pathway shows that 13 researchers have not made any change in their publication pattern. This does not support the training hypothesis. The third pathway is composed of researchers who started publishing in mainstream journals and published in non-mainstream journals in the last year. This pattern is opposite to the training hypothesis.

In Fig. 1 we present a more detailed description of the publication trajectories according to the type of journal since the interviewed researchers started publishing journal articles. The different shapes identify the indexing of their publications in each year where each row represents a researcher. This view of the publication trajectory shows a richer picture with many trajectories showing a constant movement between mainstream and nonmainstream journals. Therefore, the diverging patterns suggest that, while the training function may apply to some researchers, non-mainstream journals may have as well other functions for researchers who can publish in mainstream but sometimes choose to publish in non-mainstream. We explore this in the next two sections.

\subsubsection{Knowledge bridging}

By knowledge bridging we mean that publishing in non-mainstream journals provides a link between articles covered by mainstream journals and communities with limited or no access to them. Publications in mainstream journal are written in English and generally require payment for access. Here we present how researchers described their use of non-mainstream journals to overcome these financial and linguistic barriers. Through their publications in non-mainstream journals they introduce and adapt concepts found in mainstream journals, and in some cases these adaptations can stimulate new areas of research.

5.2.2.1. Accessibility: open access, publication in non-English language, and teaching. Some researchers expressed concern about the lack of access to mainstream journals and other barriers to the diffusion and production of knowledge. A junior researcher on agricultural sciences said: 'How is a paper of much relevance going to be used in the country if not many people read in English and students may not even have access to those databases?'. This researcher's view suggests that language and the subscription price of mainstream journals pose a reason for publishing in non-mainstream journals. These subscriptions are not affordable for many organisations, even in upper-middle income countries such as Colombia. Besides, having access to paid databases does not guarantee their use because of the language (English) barrier. For instance, a senior researcher in B \& M recalled that in her university 'faculties that had access to databases did not use them because nobody reads in English'.

In contrast to WoS and Scopus databases, Scielo and RedALyC as well as the journals they index are open access and most of them published in non-English languages. The papers in non-mainstream journals accessed through Scielo and RedALyC are also used in the classroom. They are used for teaching both at the undergraduate and postgraduate levels. A junior researcher from agronomy highlighted that 'there is no point in having ten papers in Nature, if that research is not even known by students in universities'. The words of a senior researcher in B \& M confirm the perception that research published in non-mainstream journals is relevant for education: 'I didn't want to publish in the best journals, but [in] something that could be useful to Colombian teachers'. A junior researcher from the same discipline expanded on how his research published in non-mainstream journals is used in his lectures: 'I tell my students: look, you can download my publications from this website'. The common point in these cases is that, given that the papers are published in Spanish or Portuguese, and that they are open access, non-mainstream journals become useful mechanisms to reach non-English speakers in countries that cannot always afford expensive databases and journals. Also, they allow researchers to use their articles in their roles as lecturers and supervisors. Therefore, these researchers publish in non-mainstream journals because they:

Function 3. Help to provide additional material for teaching.

Function 4. Make available open access papers. This was pointed out specifically in relation to journals indexed by Scielo and RedALyC.

Function 5. Disseminate knowledge written in English to other languages, in this case to a Spanish and Portuguese readership.

5.2.2.2. Introduction of methodologies and concepts. Seventeen researchers attested that they use non-mainstream journals to introduce subjects, concepts, or methods published in mainstream journals to a community that is not well acquainted with them. These papers can motivate others to start areas of research new to the region. For instance, a researcher in agricultural sciences explained that she published the first paper in Colombia to use $16 \mathrm{~S}$ ribosomal RNA sequencing in a non-mainstream journal. It is a method to compare and identify bacteria, usually to produce phylogenies and is important for medical microbiology and biotechnology. The aim of the interviewee was to introduce the method to the country and to show that researchers in Colombia are capable of studying groundbreaking issues. She said that after the publication of the paper other Colombian researchers adopted the method, thereby reinforcing the view that publishing in a non-mainstream journal can stimulate researchers to adopt methodologies hitherto unknown to them. The example above shows that some researchers may publish research in non-mainstream journals because they:

Function 6. Serve as vehicles to introduce concepts and methods to the local community.

\subsubsection{Knowledge gap-filling}

Twenty-one researchers attested that they use non-mainstream journals to publish topics neglected in mainstream journals. This was most noted in agricultural sciences (eight respondents), but also in B \& M (ten respondents), and chemistry (three respondents). Based on this finding, we define knowledge gap-filling as the publication of knowledge that is neglected or not found in mainstream journals. Below we analyse some of the examples provided by the interviewees in each discipline.

5.2.3.1. Agricultural sciences. A senior researcher studying Passiflora plants, which is the species producing passion fruit, pointed out the 

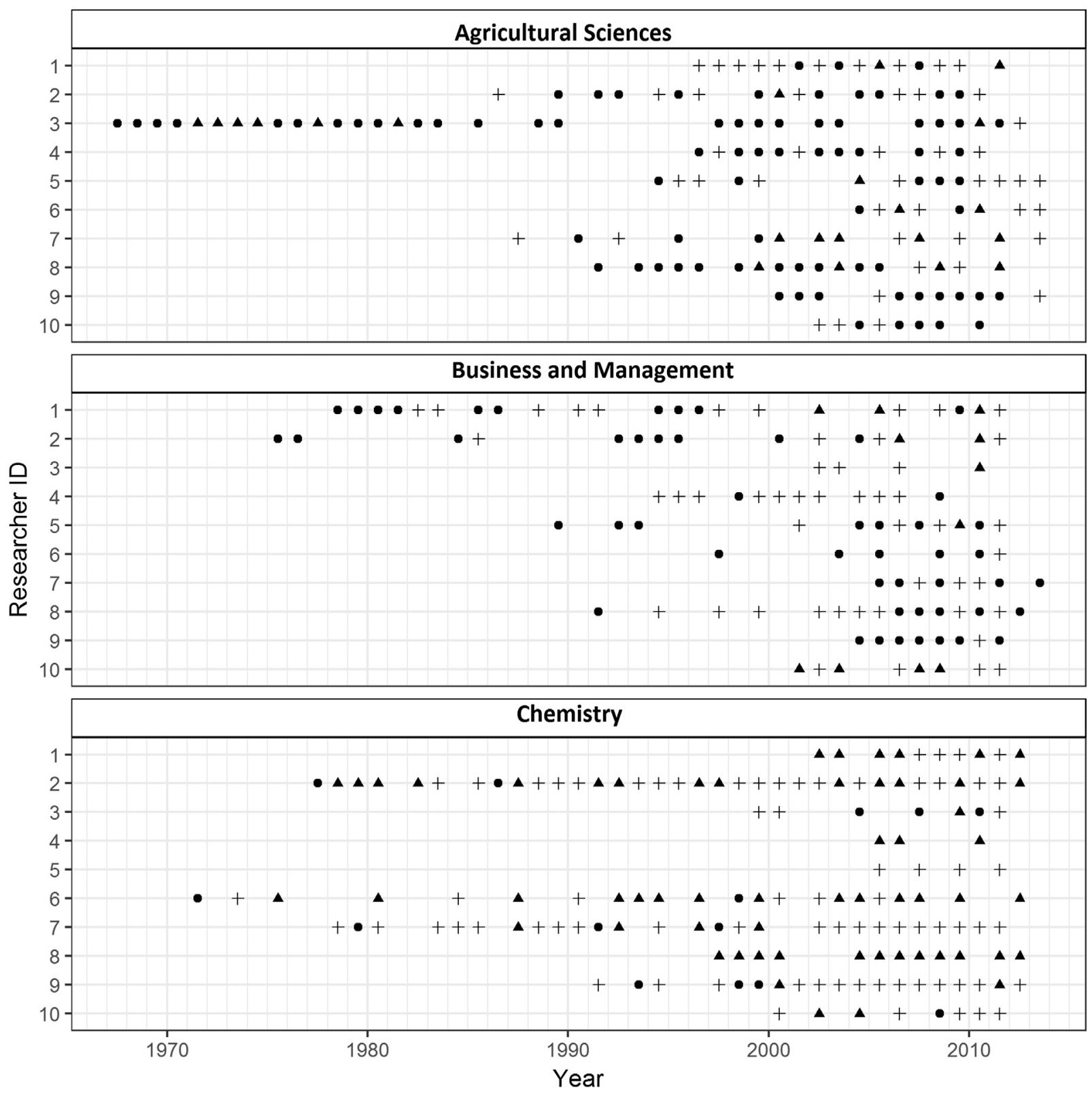

Fig. 1. Publication patterns of researchers over time.

Circle $=$ Non-mainstream, $+=$ Mainstream and non-mainstream, Triangle $=$ Mainstream .

Source: researchers' CVs, WoS, Scopus, Scielo, RedALyC.

possible subject differences between non-mainstream journals in Scielo and mainstream journals in WoS. He said:

I searched for all articles on Passiflora in the world, and an important number were found in Scielo. I think that's very good, and you know passion fruit is from here. Now, if you look for apple tree, you wouldn't find anything in Scielo. In that sense Scielo is very good. And this is not done by other indexing systems.

We used the passion fruit example to establish these subject differences. We compared the coverage of WoS and Scielo on passion fruit to see whether the papers covered by them differed and, if so, how. The title search we conducted for 'passion fruit or Passiflora edulis' from 2000 to 2010 yielded a total of 465 papers covered by WoS or Scielo. Of these $118,25 \%$ were covered by both databases. This means that $75 \%$ of the papers appeared only in one of them: 210 papers (45\%) were exclusive to WoS and 137 (30\%) to Scielo. This distribution prompted the search for indications of subject and other differences in journals covered by Scielo and WoS as pointed out by the interviewee.
In order to explore this, we analysed three sets of data (Scielo, WoS, and the Scielo-WoS journal intersection). Firstly, we listed the journals, authors, subjects, and organisations related to papers on passion fruit in each set. We then selected those with a higher frequency of papers to establish the most frequent journals, authors, subjects, and organisations. We found that WoS and Scielo have important differences on the main topics covered on passion fruit research. The majority of papers on passion fruit covered by Scielo, including Scielo-WoS, were on horticulture (49\%). In contrast, the focus of WoS was on food science technology - juice processing, pectin, and antioxidants extraction mainly. This accounted for $39 \%$ of the papers covered by it. In this sense, the foci of the databases yielded a difference in the knowledge available on passion fruit. While Scielo-indexed journals focused on its production, WoS-indexed journals focused on its transformation. ${ }^{5}$

\footnotetext{
${ }^{5}$ In a large-scale study on rice research, Rafols et al. (2016a,b) also report a relative over-representation of Food Science and Technology in WoS and Scopus.
} 


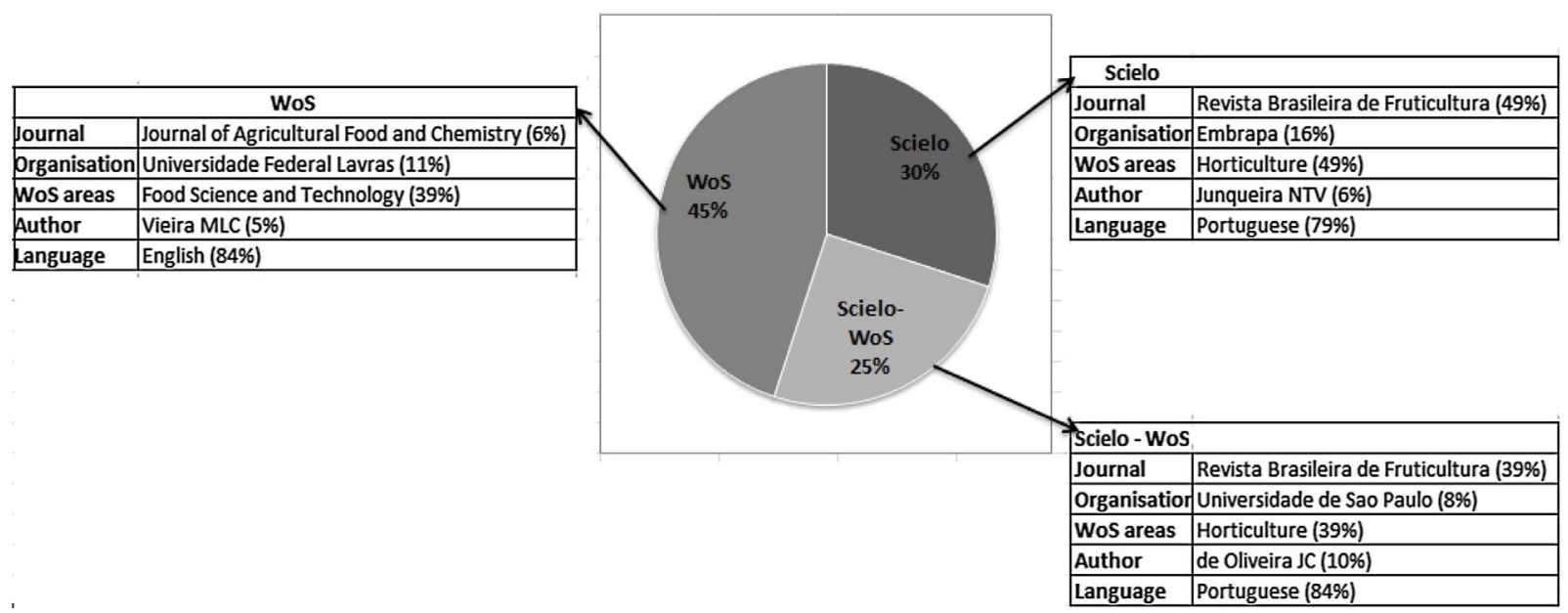

Fig. 2. Comparison between WoS (mainstream) and Scielo (non-mainstream) records on passion fruit.

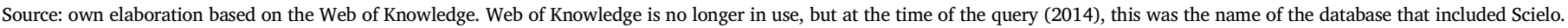

We also observed the differences at the organisational, journal, authorial and linguistic levels. For instance, Scielo showed a high contribution of Embrapa's research on production of passion fruit. Embrapa is a public institute whose mission is to develop a sustainable model of tropical agriculture for Brazil. This organisation works on the production of food, fibres, and energy (Embrapa, 2015). While it stands as the most productive organisation found in Scielo, Embrapa's visibility in WoS is blurred. In WoS, the organisation that predominates is the Universidade Federal Lavras. This means that when searching for passion fruit in WoS, the work by Embrapa is less evident and the records returned by the search are partial. Fig. 2 compares Scielo and WoS on the coverage of papers on passion fruit and shows the units with the highest frequency of papers in each set. The analysis thus confirms that for those who work on the production of Passiflora plants (which is more relevant to farmers rather than to industry), Scielo is a suitable source of knowledge. The interviewee also acknowledged that around $30 \%$ of his references were from papers in journals covered by Scielo and RedALyC. Interestingly, the dataset on passion fruit gathered for this analysis cite a similar percentage of references from Scielo as discussed below.

Based on the dataset collected of 465 publications we identified 2527 distinct articles and divided them into articles in WoS, as a proxy for articles in mainstream journals; Scielo, which roughly correspond with non-mainstream Latin American publications ${ }^{6}$; and Scielo-WoS, used to reflect the intersection between non- and mainstream articles. Fig. 3 shows the citations between the three sets. An insight from these figures is that there is a tendency for papers to cite other papers from their own group. This is more pronouncedin papers published in WoS-indexed journals (84\%) than in papers published in Scielo journals (24\%).

This analysis suggests the existence of at least two research communities with diverse interests but substantial overlaps: one on production and the other on transformation (food S \& T). Therefore, the analysis suggests that there is knowledge in non-mainstream journals that is used to address a relevant issue for Brazil: the production of an important commercial fruit. This subject would be overlooked by using only WoS, while research about transformation of the fruit would be overlooked by using only Scielo. The interface Scielo-WoS provided some but limited records on production. In this sense, the case of passion fruit research shows that a research community uses non-mainstream journals as a suitable communication channel for their scientific contributions.

Research on the African oil palm offers another example of knowledge

\footnotetext{
${ }^{6}$ Notice that non-mainstream publications are incomplete since we only access those indexed in Scielo
}

gap-filling. This plant is important especially for countries in the equatorial belt such as Colombia, Malaysia, Indonesia, Thailand, and Nigeria. Some organisations estimate that it generates more jobs per acre than any other large-scale crops such as soybeans (World Bank \& IFC, 2011, p. 15). Due to its economic importance, diseases that affect the plant have large consequences for the sector. Specifically, a disease called bud rot attacks the plant. It kills it completely potentially rendering a big part of the crop unproductive. A main problem is the uncertainty of the cause of the disease. In Colombia, research on the oil palm has been carried out mainly through Fedepalma, an association of oil palm growers. Fedepalma conducts research through its institute Cenipalma, which found that bud rot is caused by a mould called Phytophtora palmivora.

An analysis of Cenipalma's research showed that its first report on $P$. palmivora was published in a non-mainstream journal. Chronologically, the findings were published by Cenipalma's researchers as communications to farmers in the magazine Revista Palmas (Sarria et al., 2008a,b) and then in the Publindex-indexed ${ }^{7}$ journal Revista de Fitopatología Colombiana (Sarria et al., 2008a,b). Here they concluded that Phytophtora palmivora is directly related to bud rot. However, it was only in 2010 that the researchers published their results in the journal Plant Disease (Torres et al., 2010), which has been covered by WoS since 1980. When asked about the reasons why the results were published initially in non-mainstream journals, one researcher said:

In general, we do not have the pressure to publish in high impact journals and [therefore do not need to] spend years trying to publish in [the journal] Science. We tend to publish results faster, thinking of the sector that we are interested in. They have very specific problems to address.

This case suggests that the researchers published in non-mainstream journals because of the proximity to the targeted readership and because they do not have the pressure to publish in mainstream journals. As a corollary, Cenipalma's research on bud rot has been cited by other papers in mainstream journals (e.g. Martin et al., 2012) and non-mainstream journals (e.g. Benítez and García, 2014). This example shows that the original research published in a non-mainstream journal has been published both in non-mainstream and mainstream journals, in each case seeking a different audience. ${ }^{8}$ The sequence described is shown in Fig. 4.

\footnotetext{
${ }^{7}$ Publindex is a national JIS used by Colciencias to rank Colombian journals for assessment purposes.

${ }^{8}$ Although in this case the research was published both in Spanish and English, a question arises as to how many papers are published only in Spanish, which would have excluded farmers and researchers in non-Spanish speaking countries from access to relevant knowledge on bud rot. We thank an anonymous reviewer for this observation.
} 

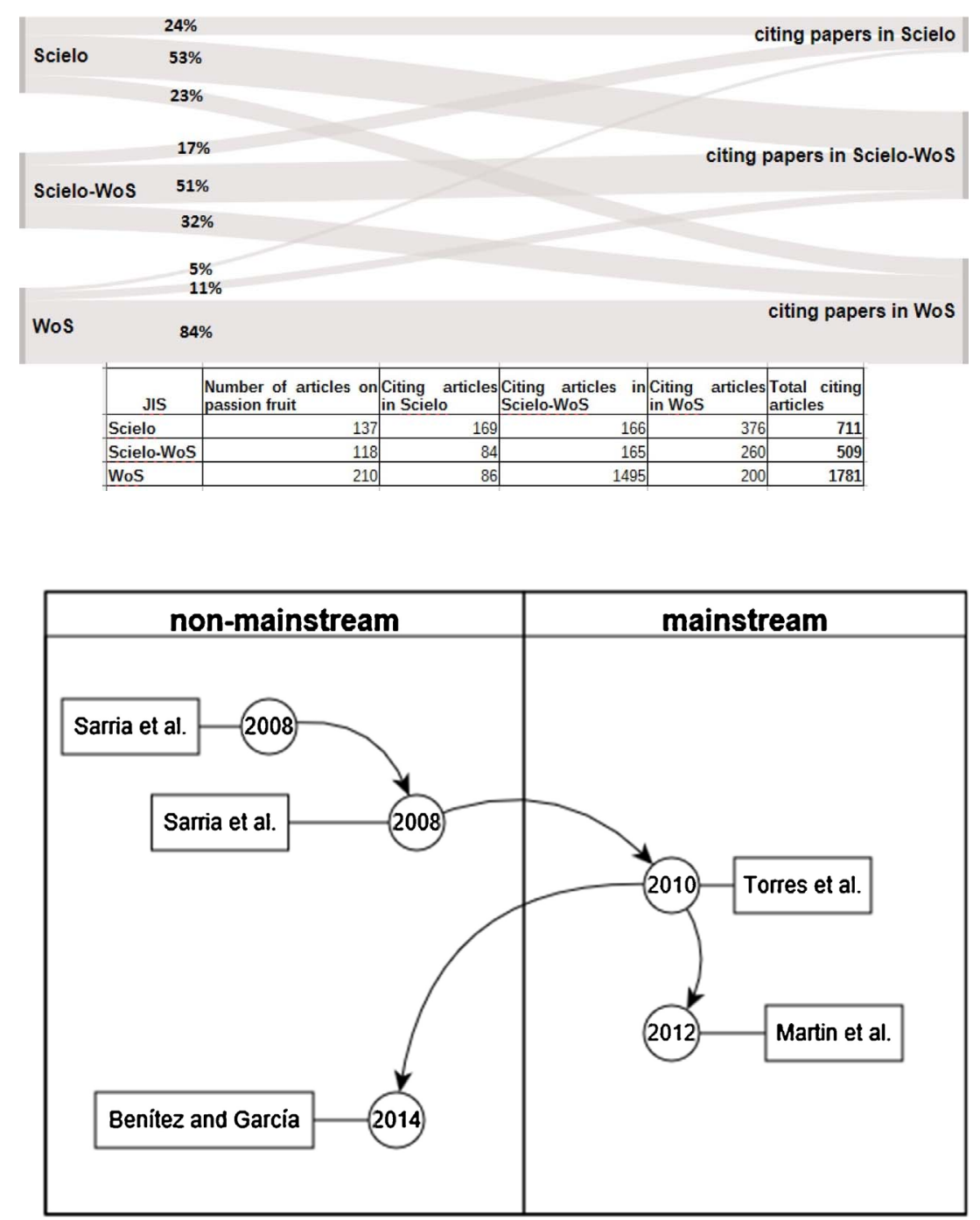

Fig. 3. Citation patterns on passion fruit in WoS (mainstream) and Scielo (non-mainstream).

Note: Citation direction is from right to left; one paper can cite different sets.

Source: own elaboration based on Web of Knowledge.
Fig. 4. Flow of citations to research on bud rot disease of palm oil tree*.

Source: own elaboration based on the papers' References

*Arrows mean 'referenced by'. Read in the direction pointed by the tip of the arrow.

Source: own elaboration based on the papers' references.

5.2.3.2. Business and management ( $B \& M$ ). Five researchers from $B$ \& $M$ supported the knowledge gap-filling function of non-mainstream journals. The researchers interviewed observed that for subjects such as B \& M, context dependence limits the scope of generalisations. An interviewee said, 'I do not think that there are big administration theories. There are some generalisations, some empirical studies, but there are not many theories'. The point of this interviewee was that in B \& M you need to study specific cases that seldom replicate findings in other settings. For instance, elaborating on context, he said, 'businesses in Colombia are different from businesses in the US'. For this reason, for the interviewee, applying frameworks produced in certain countries to understand phenomena in other countries ignores the contextual differences. His publications address the subject of innovation in Latin America. Given that most of his production is published in nonmainstream journals, this suggests that they provide an alternative channel for the study of innovation in Latin American contexts.
Furthermore, the common opinion of the researchers on B \& M was that the national and regional settings are determinants for their research. Consequently, they felt that this kind of research would not be of interest to mainstream journals. Additionally, a junior researcher maintained that in order to publish in mainstream journals she has had to change the focus of her research. For her, 'you have to transform regional research into international research. If I work on Sincelejo [a region in northern Colombia], for instance, that is not interesting for Harvard, is it?' This implies that non-mainstream journals are important for the publication of findings particularly relevant to specific regions that are outside of the interests of the gatekeepers of mainstream journals.

Similarly, a senior researcher emphasised that when he started doing research he wanted to 'produce knowledge about the Colombian entrepreneurial and managerial reality. We did not want to be the reproducers of foreign models, but to produce knowledge relevant to our country'. This relevance, another senior researcher attested, is 
threatened when researchers try to publish all their papers in mainstream journals. In his opinion, there is an idea that only WoS-indexed journals in the top citation quartiles publish 'legitimate' knowledge. The problem, for him, is that the topics addressed in those journals are at odds with the research interests of many researchers in Colombia:

$\mathrm{OK}$, knowledge is advancing there. But knowledge never, especially in the social sciences, advances abstractly. There is always a link with reality. The questions are: what reality? What issues are studied? ... Where do the questions arise? Who poses the questions? They are questions posed by people who are concerned with society, but their society.

He provided an anecdote of a paper he had been trying to publish in a Colombian journal indexed by both Scielo and WoS. He said he had difficulties publishing it in this journal because of the question he was addressing. Although the paper had not been rejected, the comments that worried him had been about his analytical framework. Specifically, he was studying the use of patents and $R \& D$ indicators to measure innovation in Colombia. In his study, he had criticised the use of these indicators because when used in Colombia, 'you can't find anything'. He had tried to show how companies in Colombia innovate through other means. In his opinion, 'if you want to know what happens here you have to forget that framework and assume that companies here do not innovate through R\&D'. This researcher criticised the journal for expecting the application of the $\mathrm{R} \& \mathrm{D}$ indicators framework to innovation in Colombia to mirror those used in advanced economies. Although he felt that there was more room for his research in non-mainstream journals, he had started to submit to journals covered by WoS because of institutional pressures. This decision, he argued, may constrain his research to the use of certain theoretical frameworks that may be unsuitable for his area of interest.

A senior researcher volunteered another example of context-dependent research published in non-mainstream journals. He said that he had published a paper on equity in Colombia in a non-mainstream journal covered by Scielo, which showed some results that looked surprising to American researchers. The American researchers had contacted him and challenged one of his results about women in Colombia having more access to jobs than women in the US do. 'I had to tell them that I am not making up the data. ... Colombia is a dynamic country. I tell them "Why don't you come to Colombia, and you will realise that it is like that"'. In summary, for these researchers from B \& M non-mainstream journals allow them to publish research that does not fit the social and geographical contexts usually covered by mainstream journals.

5.2.3.3. Chemistry. Chemistry is commonly seen as a 'basic' science, and WoS covers it better than agricultural sciences and B \& M. One may thus expect that in this discipline non-mainstream journals are not viewed as channels for publishing original research. An opinion of a junior chemist on Scielo illustrates this point:

Scielo and other regional systems... let's be honest that these databases are not very used globally, because researchers suppose that the quality is not going to be very good. And in a certain way they are right, especially in chemistry. Perhaps in social sciences and humanities they can be appropriate [because these journals tend to be regional or local], but not in chemistry. Basic science is international, and international science has some clear criteria that are fulfilled by communities with tradition.

However, a senior chemistry researcher in phytochemistry (the study of chemicals derived from plants) provided a contrasting argument. This researcher focuses on the characterisation of Colombian flora. According to him, the impact factor plays an important role in his selection of journals: 'If the impact factor is 5 , it is very good to publish there. But it is very difficult. If it is 3 , then it is OK'. However, he explained that the WoS-indexed journals with high-impact factors in his discipline had stopped publishing 'basic' research: 'If we show applicability, then it is accepted. Otherwise, it is harder. They ask for a biological applicability ... for instance, "this reduces dandruff"...'. The applicability that the researcher referred to is found in pharmacognosy, which is the study of medicine from natural sources and its findings are patentable in countries such as the US. In fact, the American Association for Pharmacognosy publishes the Journal of Natural Products, one of the journals in which this researcher has published. It is a WoS-indexed journal that is in the top impact factor quartile in three WoS categories: pharmacology, medicinal chemistry, and plant sciences. In order to publish in journals with high-impact factors such as this, the researcher has to show the application of compounds to health. Unfortunately, the interviewee said that in many cases his research group does not have the expertise to carry out health tests. To conduct the tests, he has had to collaborate with a researcher in an American institution.

If the journal's impact factor is 5 or 6 , then you need to associate with a star researcher. For instance, researcher Y. We publish with him because I give him my compounds and he says 'that substance might be useful to attack this disease'. He associates with us, but he demands that his institute goes first.

In this way, the interviewee increases his chances of publishing in a WoS-indexed high-impact journal. However, not all investigations find a clear application in industry. For this reason, the researchers need to decide what to do with their results. According to this interviewee, 'there are some journals that still accept [chemical] structures. For instance, the Cuban Journal of Chemistry ... and other journals, such as Nova or the Brazilian Journal of Chemistry. As long as it is a good quality spectrometry and produces robust results'. Surprisingly, in this case it is basic science that finds a place in non-mainstream journals. The researcher publishes in these journals research that does not have an application in the pharmaceutical industry. The value that the researcher attributes to these publications is that they increase the knowledge of Colombian biodiversity. He also asserted that 'our papers fill a cognitive gap in the country. Very few people work on the species I work on'.

Another example comes from the intersection between chemistry and agricultural sciences. This chemist and his group work on the study of red carnation. According to him, "Carnation is of great importance for our country, and for this reason we have to study it". What the researcher studies is the biochemistry of red carnation, with the aim of understanding and improving its resistance to plagues. According to him, research on red carnation from the biochemistry perspective is not as developed as it is for other flowers and crops: "on the biochemistry of Carnation there are few articles. A good number of them have been produced by our research group". The novelty of his research, which has been published mainly in non-mainstream journals, is to advance in the study of carnation resistance to the pathogen Fusarium oxysporum race 2: "We work on strain 2, which is the most widespread in Colombia. Dutch researchers work mainly on strain 1 and 8". When asked about why to publish this research in non-mainstream journals, he said: "the content of my research is good in both cases [mainstream and non-mainstream] but language [English] is a limitation [to publish in mainstream journals]".

In summary, the examples above show that these researchers publish in non-mainstream journals because they allow the publication of research that is not well covered or not found in mainstream journals, 
specifically the ones covered by WoS. The examples also reveal the significance of context (language, place, and discipline) in research activities, which in turn, contribute to the growing role of non-mainstream journals. Therefore, these researchers publish in non-mainstream journals because they:

Function 7. Allow the publication of original research that is neglected by mainstream journals.

\subsubsection{Overlapping functions}

We acknowledge that knowledge bridging (links) and knowledgegap filling (new knowledge) functions of non-mainstream journals may overlap in different cases. Accordingly we have created this "overlapping functions" category for analytical purposes. For instance, the interviews of six researchers allowed us to identify how new knowledge can emerge from the links between publications in non-mainstream and mainstream journals (the six researchers were counted for both functions). For this reason, function 7 above - introduction of methodologies and concepts - relates also to the category of knowledge gap-filling. We provide three examples to illustrate this overlap.

An interviewee provided an example of the nascent field of Latin American business history. This field emerged as a sub-discipline of business history and became a research community mainly formed by Latin American researchers (Davila 2013, p. 109) who publish in nonmainstream journals. Of the 35 papers on Latin American business history, only ten (29\%) appeared in mainstream journals in special issues. The interviewee said that Latin American researchers learned business history from the British and American pioneers (knowledge bridging). However, the process of adaptation and modification of business history concepts yielded an assimilation of knowledge that facilitated the formation of a distinctive field visible through journals covered by Scielo and RedALyC (knowledge gap-filling).

Similarly, the case of a researcher from B \& M shows that knowledge published in non-mainstream journals can be a starting point for research programmes. During her $\mathrm{PhD}$, this researcher developed a framework based on sociobiology (Wilson, 2000) to study organisations by applying the concept of production chains ${ }^{9}$ (knowledge bridging). 'When I did my PhD there was only one study using this approach. When we started publishing and going to congresses, people started to become interested in the topic in other countries, despite [being] written in Spanish'. She has published her papers only in non-mainstream journals. When asked why, she said:

Most Colombian journals [on B \& M] are multidisciplinary. For instance, Innovar has different topics within B \& M, whereas international journals are much more specific in the topics addressed. We sent a paper to a [WoS-indexed] journal and the journal was clear in saying that they don't publish on our topic. They do not disregard what we do, but it is more difficult to get accepted in those journals.

The research that she had published in non-mainstream journals has been used to start a research programme in her university. A product of this research programme was a book published in 2012 in which she compiled her studies and the work of some of her students, which could be the beginning of a new area of research in Latin America (knowledge gap-filling).

A senior researcher in B \& $M$ explained why he thought that nonmainstream journals could facilitate the emergence of new areas of study. For him, the value of non-mainstream journals is that they are more open to new questions and ways of presenting results. He thought that although some of the questions can be very intuitive, at least they generate new ideas that cannot always be published in mainstream journals. For instance, the interviewee referred to strict guidelines on the methodology as a barrier to the publication of these ideas in

${ }^{9}$ All the stages of making a product considered together (Cambridge dictionaries online 2016). mainstream journals. Besides, he thought that non-mainstream journals allow for more flexibility in the structure of the papers:

You know the standards: hypothesis, model, variables, all the conventions that are an international standard in most papers, which are OK, but one could treat the topics in a different way... for instance in the Journal of Arts Management, in which I have already published some things. Also in national journals, like the journal Innovar, that has opened certain topics. Or in a journal from the Philippines, which allows diversity of perspectives. When you want to publish in the journals with the highest impact factor, the methodologies are much stricter.

\subsection{Non-mainstream journal functions against publication patterns}

Given the differences in publication patterns among researchers, one may wonder whether the functions of non-mainstream journals are perceived differently by those focused on mainstream compared to those publishing mainly in non-mainstream publications. One might argue that publications in non-mainstream could be retrospectively rationalised as useful for training, bridging, or gap-filling only when rejected by mainstream journals. ${ }^{10}$ According to this 'sour grapes' hypothesis researchers who publish mainly in mainstream journals should not report the functions of non-mainstream journals. To check this hypothesis, we compared the functions reported by researchers with their publication patterns looking at the distributions of responses through box plots and correlations. The statistical analyses should be seen as purely exploratory given our small sample of researchers (30).

First, in Fig. 5 we present the publication patterns of researchers (vertical axis) and the functions identified by them (horizontal axis). The publication patterns are measured by the distribution of proportion of publications in mainstream journals. Each box plot shows the subset of researchers that reported a given function and the distribution of publication patterns of respondents. In the box plot, the thick line is the median; the top of the box is the maximum value of the third quartile; bottom of the box is the minimum value of the second quartile; the upper and lower thresholds are the maximum and minimum values of the whole distribution. At the right hand side of Fig. 5, the distribution for the whole population (30 respondents) is also shown. Fig. 5 illustrates that the functions are also reported by researchers with higher than average proportion of publications in mainstream journals. The median proportion of publications in mainstream for those reporting the training function is higher than for the whole population while for those reporting knowledge gap-filling and knowledge bridging are slightly lower. However, a correlation analysis shows low correlations between proportion of publications in mainstream and function reporting. ${ }^{11}$

Second, in Fig. 5 we also show the publication patterns of researchers who responded that their 'best' article was published in mainstream in comparison to those whose 'best' article was in nonmainstream journals. Researchers chose their 'best article' according to their own definition of contribution to knowledge. Again, we observe wide variation, that is researchers with higher than average proportion of publications in mainstream may consider their best publications to be in non-mainstream. When carrying out an analysis of the correlations between proportion of publications in mainstream journals and perceptions of 'best' article, we find a low correlation of 0.34 $(p=0.06)$. There are six cases of researchers (out of 15) that publish more than two thirds of their papers in mainstream journals, but still consider their best paper to be non-mainstream: one from chemistry, one from B \& M, and four from agricultural sciences. This is a surprising result considering that many researchers in the interviews also

\footnotetext{
${ }^{10}$ We thank an anonymous reviewer for suggesting this analysis.

11 Correlations are: $\mathrm{r}=0.16$ for training $(\mathrm{p}=0.40), \mathrm{r}=-0.37$ for knowledge bridging $(\mathrm{p}=0.05)$ and $\mathrm{r}=-0.47$ for gap-filling $(\mathrm{p}=0.01)$.
} 


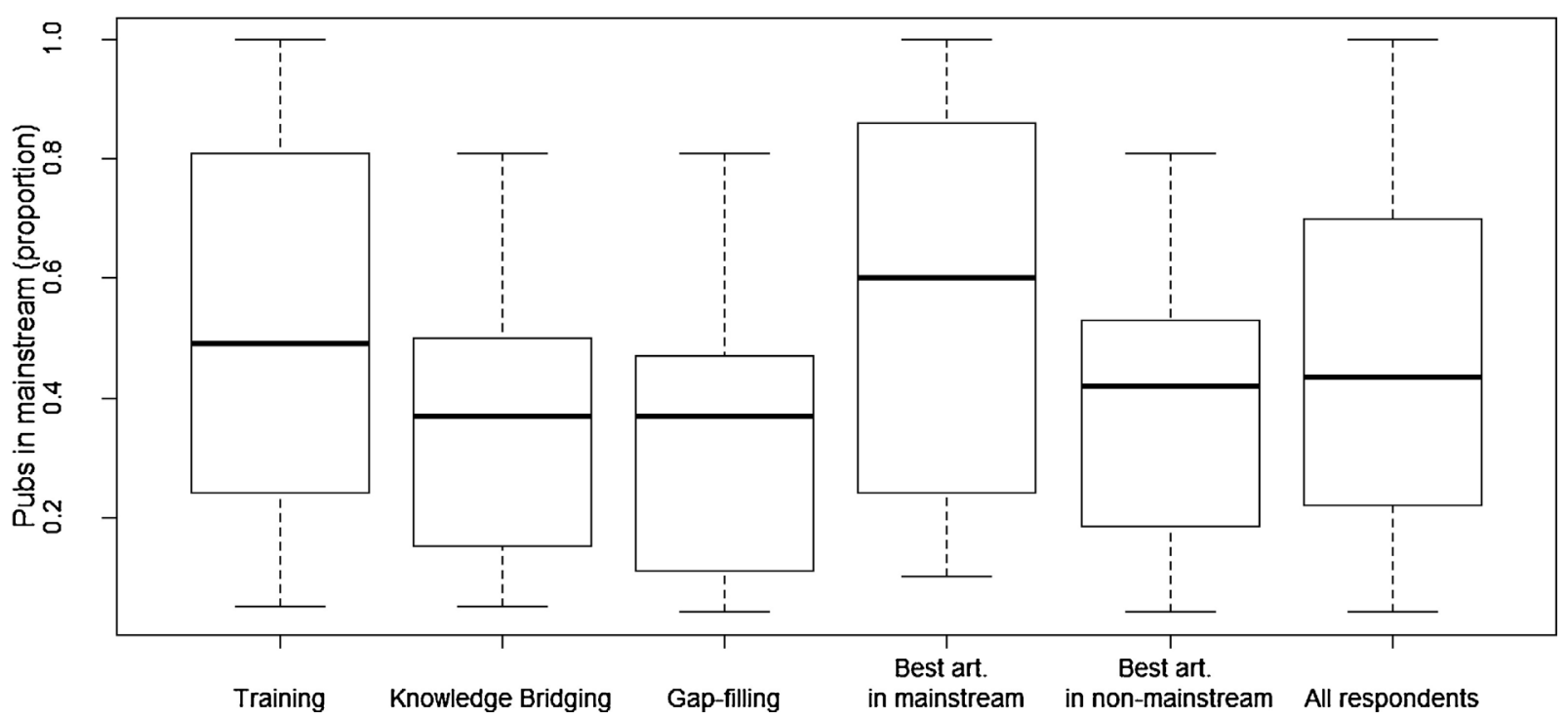

Fig. 5. Distribution of proportion of publications in mainstream for researchers reporting journal functions and journals of publication of their best article.

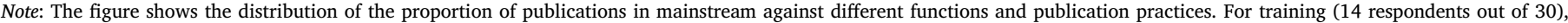

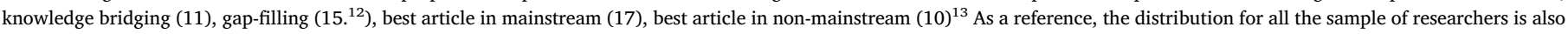
shown.

associated non-mainstream journals with lower quality.

A more detailed analysis shows that while in chemistry a perception of best paper is moderately and positively correlated with publishing in mainstream journals $(\mathrm{r}=0.5 ; \mathrm{p}=0.14)$ in agricultural sciences $(\mathrm{r}=0.17 ; \mathrm{p}=0.63)$ and $\mathrm{B} \& \mathrm{M}(\mathrm{r}=-0.01 ; \mathrm{p}=0.96)$ the correlations are negligible. This suggests a mismatch between perceptions of quality and publication patterns, especially in the latter two disciplines.

These results do not support the 'sour grapes' hypothesis because a substantial proportion of researchers in Colombia seem to recognise the complementary functions of non-mainstream journals with mainstream journals, even if their publication focus is on the latter. The fact that researchers with different proportion of articles in mainstream journals perceive the usefulness of non-mainstream journals supports the view that the choice to publish in non-mainstream is not due to a lack of capability. Researchers also make a conscious choice motivated by their audiences, as already illustrated by the narratives (e.g. passion fruit and bud rot in palm tree) in the previous section.

\subsection{Summary of findings}

The interview data yielded new insights into the reasons for researchers to publish and the functions of non-mainstream journals. Through an examination of examples suggested by the interviewees we have found that non-mainstream journals fulfil training, knowledge bridging, and knowledge gap-filling functions based on the findings below:

\section{Training}

(1) non-mainstream journals are used as training for researchers to publish in WoS-indexed journals;

(2) they are also used to introduce PhD students to academic publishing in their own language and to conduct relevant literature search;

\section{Knowledge bridging}

(3) non-mainstream journals help to provide additional material for teaching;
(4) they make available open access papers that incorporate bibliographic references from subscribed journals;

(5) they disseminate knowledge written in English to Spanish and Portuguese speakers;

(6) they serve as vehicles to introduce concepts, methods, etc. to the local community (overlaps with gap-filling);

Knowledge gap-filling

(7) non-mainstream journals allow the publication of original research neglected in mainstream journals;

Table 4 encapsulates the number of respondents for each function.

\section{Discussion and conclusions}

In this article we have examined the functions that non-mainstream journals, i.e. journals not indexed by WoS and Scopus play in communication practices of Colombian researchers. We found that training in article writing, knowledge bridging, and knowledge gap-filling were the roles of publishing in non-mainstream journals. The findings relate to the theoretical discussion on whether 'objective', universalistic notions of research quality or demands for contextualisation can explain the functions of non-mainstream journals in scientific communication.

We have found that training in article writing toward the improvement of article scientific quality partly explains how non-mainstream journals are used. According to this function, non-mainstream journals are perceived as having insufficient research rigour as judged by global peers, but they provide a space for learning. The perceived lack of quality of non-mainstream journals reflects a homogenising kind of universalism, which associates the highest editorial standards and scientific impact with publishing in mainstream journals (Moravcsik, 1987; Garfield, 1997; Testa, 2014). The perceptions contributed by researchers confirm that this association is widely shared but not highly supported by their actual publishing patterns as derived from Fig. 1.

We have also shown that researchers publish in non-mainstream journals in order to fulfil knowledge bridging and gap-filling functions. 
This provides two main insights. The first is that non-mainstream journals do publish novel research that escapes the coverage of mainstream journals (gap-filling). The second is that non-mainstream journals are not isolated from mainstream science (knowledge bridging). Therefore, 'lack of scientific quality' of their manuscripts is insufficient to explain why researchers publish in non-mainstream journals.

Filling knowledge gaps of mainstream journals is particularly important in subjects related to local knowledge ('local' at various scales: from highly localised to national to regional) (Chavarro et al., 2014). For instance, interview respondents have argued that agricultural sciences have a need for alternative publication venues because their research is likely to be related to issues of interest for national research communities and audiences (Velho, 1985), potentially benefitting local users of that knowledge. Also, the research on passion fruit discussed earlier shows the existence of diverse research areas. The research published in non-mainstream journals focused on production (horticulture, of interest to farmers), whereas the 'WoS' research mainly addressed food processing technology (of interest to industry). For evaluative purposes, research on the production of passion fruit would be underestimated by taking as a point of reference only publications covered by WoS.

The case of the oil palm disease reflects a need to disseminate the findings to a research community working with (or that is part of) oil palm's stakeholders. Although the results have global relevance, the main goal of the researchers was to make their results quickly accessible to local stakeholders, which led them to publish in non-mainstream journals. This example also shows that there are cases in which nonmainstream precede mainstream journals in diffusing content that is novel and valuable globally. This function of knowledge gap-filling by non-mainstream journals is not exclusive to agricultural sciences. The examples show that non-mainstream journals in B \& M publish new insights on business history, and non-mainstream chemistry journals publish new research on botany that is relevant for biodiversity and research on red carnation that is relevant for a sector.

The bridging function is manifest in the way non-mainstream journals are linking their readers to topics appearing in subscribed English language journals. Mainstream journals pose linguistic and financial challenges for a readership in non-native English speaking, lowincome and middle-income countries. As most of the non-mainstream journals in Latin America are open access, and are published in Spanish or Portuguese, they help to overcome the barriers to access knowledge in mainstream journals. Through the introduction of concepts and methodologies found in mainstream journals, non-mainstream journals connect closed access research in English to open access research in other languages.

We draw one major theoretical insight and one main policy reflection from the above observations. On the theory side, these findings challenge an exclusive universalistic explanation based on quality standards for publishing in non-mainstream journals.

In agreement with Mertonian motivations to publish (Merton, 1973a), most of the researchers mentioned the communication of their contributions to knowledge as one of the drivers for publication. However, when asked about the choice of journals, we learnt that such communication could take place within or between different research communities: some more international, some national or regional, some more embedded in the context of application or relevant stakeholders (Hicks, 2004; Piñeiro and Hicks, 2015). Since all journals (mainstream and non-mainstream) are located in specific contexts, they produce a representation of knowledge from specific perspectives. Therefore, each journal will have a specific notion of quality that is consistent with the methods, objects and interests of its research community (Weinberg, 1963, p. 162). By bringing in context, we can interpret the functions observed of nonmainstream journals as serving different contextual needs of different research communities:
- In training, the primary need is to help researchers learn how to carry out research, to increasingly adopt the global quality standards and to eventually publish in mainstream journals as a way of joining the 'international' (generally centred around the US and the EU) research communities.

- In knowledge bridging, non-mainstream journals facilitate the access, via dissemination and adaptation, of knowledge from 'international' communities to regional or national research communities and stakeholders who may not be English-speaking or may not afford journal subscriptions.

- In knowledge gap-filling, non-mainstream journals allow to publish and disseminate knowledge that is novel and relevant to local research communities and their contexts, but which is not perceived as important by the editors and gatekeepers of mainstream journals.

These insights reinforce the argument advanced by Vessuri et al. (2014), Bianco et al. (2016), and others, about the importance of context in research production and evaluation. Therefore, non-mainstream journals (in particular those in Scielo and RedALyC) should not be seen just as 'publication favelas' (Beall, 2015), but as part of a cumulative process of certification of new knowledge by specific research communities (Merton, 1973b).

Our policy contribution is related to evaluation systems that are not based on peer recognition, but on expert systems, such as journal rankings (Whitley and Gläser, 2007; Paradeise and Thoenig, 2013). By using indexation in WoS and Scopus as criterion, Colombian evaluation exercises are judging quality according to standards of the 'international' research communities (generally centred in the global north), who publish in mainstream journals. The 'universalistic' standards of these evaluations are in agreement with the perspective of publishing in non-mainstream journals as learning, but are very likely to disregard the value of contribution to national or local research communities in the form of knowledge bridging and gap filling. For this reason, dominant research assessments based on journals underestimate the knowledge produced in countries, disciplines, and languages that are not the foci of mainstream journals. The consequence is that nonmainstream journals are not appraised as valid venues for the communication of valuable new knowledge. At most, they will be considered as journals for mere training for researchers to build research capability.

To foster research and knowledge that can benefit society, research evaluation policies will want to value the communication roles of nonmainstream journals. Such policy considerations may be particularly relevant to low and middle income countries such as Colombia, regions such as Latin America, and more generally to the global south. Although the empirical results of this research are circumscribed to Colombia, the knowledge gap-filling and knowledge bridging functions described in this paper are not limited to this country. They can help to illuminate the knowledge neglected by universalistic research evaluation in other marginalised or 'peripheral' contexts (i.e. in communities with non-hegemonic languages, in disciplines treated as 'minor' or 'lower', in socially disenfranchised areas), in particular when considering knowledge exchange with non-academic experts or for unconventional topics (Vessuri et al., 2014). For this reason, policy awareness and recognition of the knowledge gap-filling and knowledge bridging functions of non-mainstream journals can improve the communication, reputation, and utilisation of research with the potential to address pressing social needs. ${ }^{12,13}$

\footnotetext{
${ }^{12}$ Knowledge bridging and gap-filling taken independently (minus six overlapping cases).

${ }^{13}$ When asked about their best publication, three respondents did not choose a best article.
} 
Table 4

Functions of non-mainstream journals by number of respondents.

\begin{tabular}{|c|c|c|c|c|c|c|c|c|c|c|c|c|c|}
\hline \multirow[t]{2}{*}{ Functions } & \multicolumn{3}{|c|}{ Main functions } & \multirow{2}{*}{$\begin{array}{l}\text { Total } \\
\text { respondents }\end{array}$} & \multicolumn{3}{|l|}{ Discipline } & \multicolumn{2}{|c|}{ Organisation } & \multicolumn{2}{|c|}{ Experience } & \multicolumn{2}{|c|}{ Gender } \\
\hline & Training & Bridging & Gap-filling & & $\begin{array}{l}\text { Agricultural } \\
\text { sciences }\end{array}$ & $\mathrm{B} \& \mathrm{M}$ & Chemistry & Public & Private & Junior & Senior & $\mathrm{F}$ & M \\
\hline 1 Training & $\mathrm{X}$ & & & 13 & 5 & 4 & 4 & 9 & 4 & 6 & 7 & 2 & 11 \\
\hline 2 Introduction to writing & $\mathrm{X}$ & & & 8 & 1 & 6 & 1 & 6 & 2 & 4 & 4 & 2 & 6 \\
\hline 3 Teaching & & $\mathrm{X}$ & & 8 & 0 & 5 & 3 & 6 & 2 & 5 & 3 & 5 & 3 \\
\hline 4 Accessibility & & $\mathrm{X}$ & & 7 & 4 & 3 & 0 & 3 & 4 & 3 & 4 & 3 & 4 \\
\hline 5 Dissemination in other languages & & $\mathrm{X}$ & & 6 & 2 & 2 & 2 & 3 & 3 & 3 & 3 & 3 & 3 \\
\hline $\begin{array}{l}6 \text { Introduction of concepts and } \\
\text { methodologies }\end{array}$ & & $\mathrm{X}^{14}$ & $\mathrm{X}$ & 17 & 4 & 10 & 3 & 10 & 7 & 4 & 13 & 8 & 9 \\
\hline 7 Introduction of new research & & $\mathrm{X}$ & $\mathrm{X}$ & 21 & 8 & 10 & 3 & 14 & 7 & 6 & 15 & 5 & 16 \\
\hline
\end{tabular}

\section{Acknowledgements}

We are grateful for the insightful comments of two Research Policy anonymous peer reviewers. We thank Ed Steinmueller, Ben Martin, Tomasso Ciarli, Saurabh Aurora, Andy Stirling, Matías Ramírez, Rocío Alvarez, Tomás Saieg, Andrea Laplane, Edwin Cristancho and other colleagues at SPRU for many fruitful discussions. We also thank two SPRU Working Paper Series peer reviewers. We are also indebted to the interviewees that made this research possible for their time and invaluable help. Diego Chavarro was sponsored by Colciencias for his $\mathrm{PhD}$ at SPRU (University of Sussex) and also received a grant to conduct research in Colombia from the Doctoral School of the University of Sussex. The Facultad de Administración de Empresas de la Universidad Externado de Colombia provided him facilities to do his fieldwork and guidance from Luis Antonio Orozco and Carlos Restrepo. In addition, EU-SPRI awarded him a grant to do a research visit at INGENIO (CSICUPV), València, supervised by Jordi Molas Gallart. This paper would not have been possible without the support of these organisations and colleagues.

\section{Appendix A. Supplementary data}

Supplementary data associated with this article can be found, in the online version, at http://dx.doi.org/10.1016/j.respol.2017.08.002.

\section{References}

Aguado-López, E., Becerril-García, A., Arriola, M., Martínez-Domínguez, N.D., 2014. Iberoamérica en la ciencia de corriente principal (Thomson Reuters/Scopus): una región fragmentada. Interciencia 39 (8), 570-579.

Arvanitis, R., Gaillac, J., 1992. Proceedings of the International Conference on Science Indicators for Developing Countries. Éditions De l'ORSTOM, Paris (Available at:). http://horizon.documentation.ird.fr/exl-doc/pleins_textes/pleins_textes_6/ colloques2/36935.pdf.

Bazerman, C., 1988. Shaping Written Knowledge: The Genre and Activity of the Experimental Article in Science. University of Wisconsin press, Madison, WI.

Benítez, É., García, C., 2014. The history of research on oil palm bud rot (Elaeis guineensis Jacq.) in Colombia. Agrono. Colomb. 32 (3), 390-398.

Bianco, M., Gras, N., Sutz, J., 2016. Academic Evaluation: Universal Instrument? Tool for Development? Minervapp. 1-23. http://dx.doi.org/10.1007/s11024-016-9306-9J.

Bortagaray, I., Ordóñez-Matamoros, H.G., 2012. Introduction to the special issue of the review of policy research: innovation, innovation policy, and social inclusion in developing countries. Rev. Policy Res. 29, 669-671.

Braun, V., Clarke, V., 2006. Using thematic analysis in psychology. Qual. Res. Psychol. 3 (2), 77-101. http://dx.doi.org/10.1191/1478088706qp063oa.

Burrows, Roger, 2012. Living with the h-index? Metric assemblages in the contemporary academy. Sociol. Rev. 60 (2), 355-372.

Chavarro, D., Tang, P., Rafols, I., 2014. Interdisciplinarity and research on local issues: evidence from a developing country. Res. Eval. 23, 195-209. http://dx.doi.org/10. 1093/reseval/rvu012.

Chavarro, D., 2017. Universalism and Particularism: Explaining the Emergence and Development of Regional Indexing Systems (doctoral Thesis). SPRU - University of Sussex, Brighton, UK (Retrieved from SPRU thesis collection).

Cole, S., 1983. The hierarchy of the sciences? Am. J. Sociol. 89 (1), 111-139.

\footnotetext{
${ }^{14}$ There is an overlap of six researchers between functions 6 and 7.
}

Crane, D., 1967. The gatekeepers of science: some factors affecting the selection of articles for scientific journals. Am. Sociol. 2, 195-201.

San Francisco Declaration on Research Assessment. (Retrieved from:). http://www.ascb. org/dora/.

Davila, C., 2013. The current state of business history in Latin America: business history in Latin America. Aust. Econ. Hist. Rev. 53 (2), 109-120. http://dx.doi.org/10.1111/ aehr.12006.

Davis, C., Eisemon, T., 1989. Mainstream and non mainstream scientific literature in four peripheral Asian scientific communities. Scientometrics 15 (3), 215-239.

Delgado, G., Forero, E., Ponce, W., Mondragon, F., et al., 2016. Carta dirigida al subdirector de Colciencias. Propuesta ajuste publindex-colciencias. El Espectador. (Retrieved from). https://innovacionyciencia.com/blog/carta_dirigida_al_ subdirector de colciencias propuesta ajuste publindex colciencias.

Quem Somos - Portal Embrapa. (Retrieved from:). https://www.embrapa.br/quemsomos.

Estrada-Mejía, C., Forero-Pineda, C., 2010. The quest for visibility of scientific journals in Latin America. Learn. Publ. 23, 237-252.

Evans, J.A., Shim, J.M., Ioannidis, J.P., 2014. Attention to local health burden and the global disparity of health research. PLoS One 9 (4), e90147.

Fry, J., Oppenheim-DIS, C., Creaser, C., Johnson, W., Summers, M., White-LISU, S., et al., 2009. Communicating Knowledge: How and Why Researchers Publish and Disseminate Their Findings. JISC: Supporting Paper, 2. (Retrieved:). http://www.rin. ac.uk/system/files/attachments/Communicating-knowledge-focus-groups.pdf.

Gómez-Morales, Y., Restrepo, E., Vargas, E., Vélez cuartas, G., et al., 2016. ¿Cuál es la mejor forma para medir el desarrollo científico en el país? El Espectador. (Retrieved from:). http://www.elespectador.com/noticias/ciencia/cual-mejor-forma-medir-eldesarrollo-cientifico-el-pais-articulo-650615.

Garfield, E., 1995. Quantitative analysis of the scientific literature and its implications for science policymaking in Latin America and the Caribbean. Relation 29, 87-95.

Garfield, E., 1997. A statistically valid definition of bias is needed to determine whether the Science Citation Index discriminates against third world journals. Curr. Sci. 73 (8), 639-641.

Gibbs, W.W., 1995. Lost science in the third world. Sci. Am. 273, 92-99.

Gläser, J., Laudel, G., 2016. Governing science. Eur. J. Sociol. 57, 117-168. http://dx.doi. org/10.1017/S0003975616000047.

Guédon, J.C., 2001. In Oldenburg's Long Shadow: Librarians, Research Scientists, Publishers, and the Control of Scientific Publishing. Association of Research Libraries, Washington, DC.

Guédon, J.C., 2007. Open Access and the Divide Between 'mainstream' and Peripheral Science. (Retrieved from:). http://eprints.rclis.org/10778/1/Brazil-final.pdf.

Hess, D., 2007. Alternative Pathways in Science and Industry. MIT Press, Cambridge, MA.

Hess, D., 2016. Undone Science: Social Movements, Mobilized Publics, and Industrial Transitions. MIT Press, Cambridge, MA.

Hicks, D., Wouters, P., Waltman, L., de Rijcke, S., Rafols, I., 2015. Bibliometrics: the Leiden manifesto for research metrics. Nature 520, 429-431. http://dx.doi.org/10. 1038/520429a.

Hicks, D., 2004. The four literatures of social science. Handbook of Quantitative Science and Technology Research. Springer, Netherlands, pp. 473-496.

Klein, D., Chiang, E., 2004. The social science citation index: a black box with an ideological bias? Econ. J. Watch 1 (1), 134-165.

Larivière, V., Macaluso, B., 2011. Improving the coverage of social science and humanities researchers' output: the case of the Érudit journal platform. J. Am. Soc. Inf. Sci Technol. 62 (12), 2437-2442. http://dx.doi.org/10.1002/asi.21632.

Larivière, V., Haustein, S., Mongeon, P., 2015. The oligopoly of Academic Publishers in the digital era. PLoS One 10,1-15. http://dx.doi.org/10.1371/journal.pone. 0127502.

Lemarchand, G., 2010. National Science, Technology and Innovation Systems in Latin America and the Caribbean. Unesco, Montevideo, Urugay.

Lemarchand, G., 2012. The long-term dynamics of co-authorship scientific networks: Iberoamerican countries (1973-2010). Res. Policy 41 (2), 291-305. http://dx.doi. org/10.1016/j.respol.2011.10.009.

Lillis, T., Curry, M., 2010. Academic Writing in a Global Context. Routledge, Abingdon.

Martin, F.N., Abad, Z.G., Balci, Y., Ivors, K., 2012. Identification and detection of Phytophthora: reviewing our progress, identifying our needs. Plant Dis. 96 (8), 1080-1103.

Meneghini, R., Packer, A.L., 2007. Is there science beyond English? Initiatives to increase 
the quality and visibility of non-English publications might help to break down language barriers in scientific communication. EMBO Rep. 8, 112-116. http://dx.doi. org/10.1038/sj.embor.7400906.

Meneghini, R., Mugnaini, R., Packer, A.L., 2006. International versus national oriented Brazilian scientific journals. A scientometric analysis based on SciELO and JCR-ISI databases. Scientometrics 69, 529-538.

Merton, R., 1973a. The normative structure of science. In: Storer, N. (Ed.), The Sociology of Science. The University of Chicago Press, Chigago and London, pp. 267-278.

Merton, R., 1973b. The Matthew effect in science. In: Storer, N. (Ed.), The Sociology of Science. The University of Chicago Press, Chigago and London, pp. 439-460.

Moravcsik, M., 1987. In the beholder's eye: a possible reinterpretation of Velho's results on Brazilian agricultural research. Scientometrics 11 (1-2), 53-57.

Mugnaini, Rogério, 2015. Journal evaluation cycle in brazil: virtuous path or patchwork? In: XVI Encontro Nacional de Pesquisa em Ciência da Informação. Joao Pessoa, September.

Myers, G., 1985. Texts as knowledge claims: the social construction of two biology articles. Soc. Stud. Sci. 15, 593-630.

Nagpaul, P., 1995. Contribution of Indian universities to the mainstream scientific literature: a bibliometric assessment. Scientometrics 32 (1), 11-36. http://dx.doi.org/ 10.1007/BF02020186.

Indicadores De Ciencia Y Tecnología. OCyT, Bogotá, Colombia (Retrieved from:). http:// ocyt.org.co/Portals/0/LibrosPDF/indicadores\%202015_web.pdf.

Ordóñez-Matamoros, H.G., Cozzens, S.E., Garcia, M., 2010. International Co-authorship and research team performance in Colombia. Rev. Policy Res. 27 (4), 415-431.

Paradeise, C., Thoenig, J.C., 2013. Academic institutions in search of quality: local orders and global standards. Organ. Stud. 34 (2), 189-218.

Piñeiro, C., Hicks, D., 2014. Reception of Spanish sociology by domestic and foreign audiences differs and has consequences for evaluation. Res. Eval. 24 (1), 78-89.

Rafols, I., Leydesdorff, L., O’Hare, A., Nightingale, P., Stirling, A., 2012. How journal rankings can suppress interdisciplinary research: a comparison between Innovation Studies and Business \& Management. Res. Policy 41 (7), 1262-1282. http://dx.doi. org/10.1016/j.respol.2012.03.015.

Rafols, I., Ciarli, T., Chavarro, D., 2016a. In: Under-reporting Research Relevant to Local Needs in the Global South. Database Biases in the Representation of Knowledge on Rice. Contested Agronomy Conference, Brighton, UK. (Retrieved from:). https:// pdfs.semanticscholar.org/c784/ac36533a87934e4be48d814c3ced3243f57a.pdf.

Rafols, I., Molas-Gallart, J., Chavarro, D., Robinson-Garcia, N., 2016b. On the Dominance of Quantitative Evaluation in 'Peripheral' Countries: Auditing Research with Technologies of Distance. SSRN (Retrieved from:). https://papers.ssrn.com/sol3/ papers2.cfm?abstract_id $=2818335$.

Sarria, G.A., Torres, G.A., Aya, H.A., Ariza, J.G., Rodríguez, J., Martínez, G., 2008a. Phytophthora sp. es el responsable de las lesiones iniciales de la Pudrición del cogollo (PC) de la Palma de aceite en Colombia. Rev. Palmas 29 (3), 31-41.

Sarria, G.A., Torres, G.A., Vélez, D.C., Rodríguez, J., Noreña, C., Varon, F., et al., 2008b. Caracterización morfológica y molecular de Phytophthora palmivora agente causal de las lesiones iniciales de la Pudrición del cogollo (PC) de la palma de aceite en
Colombia. Fitopatol. Colomb. 32 (2), 43.

Scielo, 2015. Rebuttal to the Blog Post Is SciELO a Publication Favela? Authored by Jeffrey Beall. (Retrieved from:). https://blogdodijaci.blogspot.com.es/2015/08/ nota-de-repudio-ao-artigo-is-scielo.html.

Spinak, E., 1996. Quantitative analyses of scientific literature and their validity for judging Latin American production. Boletín de la Oficina Sanitaria Panamericana (OSP) 120, 139-147.

Stirling, A., 2015. Towards Innovation Democracy? Participation, Responsibility and Precaution in the Politics of Science and Technology, STEPS Working Paper 78. STEPS Centre, Brighton (Retrieved from:). http://steps-centre.org/publication/ innovation-democracy-stirling/.

Testa, J., 2014. The Thomson Reuters Journal Selection Process. (Retrieved from:). http://wokinfo.com/essays/journal-selection-process/.

Torres, G.A., Sarria, G.A., Varon, F., Coffey, M.D., Elliott, M.L., Martinez, G., 2010. First report of bud rot caused by Phytophthora palmivora on African oil palm in Colombia. Plant Dis. 94 (9), 1163.

van Leeuwen, T., Moed, H., Tijssen, R., Visser, M., van Raan, A., 2001. Language biases in the coverage of the science citation index and its consequences for international comparisons of national research performance. Scientometrics 51 (1), 335-346.

Velho, L., 1985. Science in the Periphery: a Study of the Agricultural Scientific Community in Brazilian Universities (doctoral Thesis). SPRU - University of Sussex, Brighton, UK (Retrieved from SPRU thesis collection).

Velho, L., Krige, J., 1984. Publication and citation practices of Brazilian agricultural scientists. Social Stud. Sci. 14 (1), 45-62.

Vessuri, H., Guédon, J.C., Cetto, A.M., 2014. Excellence or quality? Impact of the current competition regime on science and scientific publishing in Latin America and its implications for development. Curr. Sociol. 62 (5), 647-665. http://dx.doi.org/10. $1177 / 0011392113512839$.

Vessuri, H., 1995. Recent strategies for adding value to scientific journals in Latin America. Scientometrics 34 (1), 139-161.

Whitley, R., Gläser, J. (Eds.), 2007. The Changing Governance of the Sciences: the Advent of Research Evaluation Systems. Springer, Dordrecht, the Netherlands.

Whitley, R., Gläser, J., 2012. Organising Science: The Increasingly Formal Structuring of Academic Research - Sub-theme 17 of the EGOS Conference. (Retrieved from:). http://www.egos2012. net/2011/06/organising-science-the-increasingly-formalstructuring-of-academic-research/.

Wilsdon, J., Allen, L., Belfiore, E., Campbell, P., Curry, S., Hill, S., et al., 2015. The Metric Tide. Independent Review of the Role of Metrics in Research Assessment and Management. http://dx.doi.org/10.13140/RG.2.1.4929.1363.

Wilson, E.O., 2000. Sociobiology: The New Synthesis, 25th anniversary ed. Belknap Press of Harvard University Press, Cambridge, Mass.

World Bank and IFC, 2011. The World Bank Group Framework and IFC Strategy for Engagement in the Palm Oil Sector. (Retrieved from:). http://www.ifc.org/wps/ wcm/connect/159dce004ea3bd0fb359f71dc0e8434d/WBG + Framework + and + IFC + Strategy_FINAL_FOR + WEB.pdf?MOD = AJPERES.

Yin, R., 2009. Case Study Research: Design and Methods, 4th ed. Sage, Los Angeles, CL. 